\title{
Mine is Bigger than Yours! Narcissism Predicts Biases in Perceived Head Size
}

\author{
Minna Lyons \\ University of Liverpool, UK
}

\author{
Victoria Blinkhorn \\ University of Sunderland, UK
}

\author{
Elizabeth S. Collier, Marco Bertamini \\ University of Liverpool, UK
}

\begin{abstract}
The expression big headed is often used to describe narcissists, however is it possible that this term signals a bias in how narcissists perceive themselves? We tested whether narcissistic traits predicted biases in the estimated size and weight of specific body parts, including head circumference and brain weight. In two questionnaire-based studies, participants estimated the size or weight of parts of their body. In Study $1(n=316)$, we found that the Leadership/Authority facet of narcissism significantly predicted greater estimates of head circumference in men, but lower estimates of head circumference in women. In Study $2(n=275)$, we found that when a sexspecific average head circumference was not provided, Leadership/Authority predicted greater estimates of head circumference overall. We present evidence that narcissism predicts biases in estimated head size and brain weight, but that the precise nature of these biases is dependent on the provided frame of reference for body size. These results are discussed with reference to within-sex competitive strategies, perceived intelligence and stereotypes for male and female attractiveness.
\end{abstract}

Key words: narcissism, body perception, head size, competitive strategies, sex differences

\section{Introduction}

Narcissism is a well-researched personality trait that relates to persistent illusions of one's superiority in comparison to other people. Individuals with high levels of narcissism have the tendency to over-estimate and self-enhance their characteristics in multiple different domains (Grijalva\&Zhang, 2016). For example, narcissism is associated with perceiving oneselfas dominant

Correspondence concerning this article should be addressed to Dr. Victoria Blinkhorn, University of Sunderland.

E-mail: dr.victoriablinkhorn@outlook.com

Received January 15, 2019
(Grijalva \&Zhang, 2016; Rauthmann, 2012), creative (Goncalo, Flynn, \& Kim, 2010), attractive (Gabriel, Critelli, \& Ee, 1994), and intelligent (Campbell, Rudich, \& Sedikides, 2002). In addition, narcissisticindividuals engage in constant downward social comparison (Krizan \& Bushman, 2011), thinking that theyare better than other people around them. It is possible that the selfenhancement and social comparison tendencies are also represented in the way that narcissistic individuals view their bodies. Indeed, the body can act as a powerful vessel for a person's conception of the "self" and influence the manner in which peopleinteract with others(Tsakiris, 2017). The human body has tremendous historical and cultural significance. Many of our emotions, experiences, and behaviours are based on embodied cognition, which is reflected in the linguistic 
metaphors that link to different body parts (Alberti, 2016; Gibbs, 2003). In this study, we were interested in exploring how narcissism related to people's perceptions of the size of various parts of their bodies.

The relationship between narcissism and body perceptions has been investigated in several studies, indicating that maladaptive aspects of narcissism have a connection with negative body image in both sexes (Purton et al., 2018; Swami, Cass, Waseem, \& Furham, 2015), whereas more adaptive aspects of narcissism are associated with a positive body image (Carrotte \& Anderson, 2019; Lipowska \& Lipowski, 2019). In the present study, our primary interest was not body image, but the perception of the size of socially and culturally relevant body parts, such as the heart, brains, head circumference, lungs, and hands. We often use body parts as a metaphor for something else (e.g., "Maria has a big heart" means that Maria is a kind person), and people are harnessed with an intuitive knowledge about the meaning of these metaphors (Gibbs, 2003).

There are reasons to expect that people with high levels of narcissism think that their brains and heads are bigger than those of others. For instance, brain volume (Nave et al., 2019; Pietschnig et al., 2015) and head circumference (Bakhiet et al., 2017) have been related to better performance on intelligence tasks and it seems reasonable to suggest that narcissistic individuals may overestimate the size of these body parts as a reflection of their perceived greater intelligence. Furthermore, in colloquial English, talking about a person as "big brained" is a reference to their intelligence, and referring to someone as being "big headed" is denoting how overconfident they are. As narcissistic individuals think they are intelligent (Campbell et al., 2012; Grijalva \& Zhang, 2016), and happy to admit their over confidence (Konrath, Meier, \& Bushman, 2014), we would expect that they have inflated estimations of their brain weight and head circumference. Interestingly, research has shown that people consistently over-estimate the size of their head compared to the head of other individuals (Bianchi, Savardi, \& Bertamini, 2008). The authors suggested that it could be due to a self-serving bias, as it is possible that people use head size as a proxy for intelligence (Bianchi et al., 2008).

Although brain size and head circumference were our primary interest, we also explored the relationship between narcissism and size estimations of other body parts. For example, lung size has been associated with good health and exercise, something that narcissistic individuals are known to beconcerned about (Bruno etal., 2014). Thus, we expected a positive correlation between narcissism and estimated lung size. However, heart metaphors based around kindness and empathy (Alberti, 2016), are characteristics not typical in narcissistic individuals (e.g., Jonason, Lyons, Bethell, \& Ross, 2013). One of the few domains where narcissists do not show an overestimation bias is in communal traits, behaviours that benefit other people(Grijalva \&Zhang, 2016), indicating a "big heart". For this reason, we did not expect a relationship between narcissism and estimations ofheart weight.

In addition to exploring the relationship between narcissism and perceptions of size of different body parts, we were interested in whether narcissism also influences these perceptions differently in men and women. Research has suggested that in comparison to women, narcissism predicts a greater self-enhancement of attractiveness and intelligence in men (Gabriel, Critelli, \& Ee, 1994). Thus, it is reasonable to propose that any associations will be of larger magnitude in men. Furthermore, we intended to investigate different aspects of narcissism, as identified in the Narcissistic Personality Inventory (NPI; Raskin \& Terry, 1988). Ackerman et al. (2011) suggested that the NPI contains three factors; adaptive facet of Leadership/Authority (e.g., assertiveness, self-enhancement), and 
maladaptive facets of Grandiose Exhibitionism (e.g., attention seeking) and Entitlement/ Exploitativeness (e.g., devaluating and exploiting others). We expected that the self-enhancing Leadership/Authority facet would have the strongest relationship with inflated size estimations of body parts.

\section{Study 1}

In Study 1, we tested whether narcissism predicted biases in estimates of the size and weight of specific body parts, when given an average value for a typical man or a woman. Providing participants with an average value allowed us to ensure that all participants were making their estimate with some frame of reference and were therefore less likely to wildly guess, while simultaneously allowing us to check whether narcissism would predict an over or underestimation relative to the average. Since we were unable to measure the actual size and weight of the specified body parts, we instead considered the average as being a baseline value that was consistent across all participants.

\section{Method}

\section{Participants}

The sample consisted of 316 participants (mean age $=26.80, S D=11.30 ; 23.10 \%$ male) . Participants were recruited by advertising an online questionnaire to students at a university in North-West of England, who could participate for course credit. The questionnaire was also shared with the wider community via social media. Participants were mostly of British, Northern American or European nationality.

\section{Materials}

To measure perceived body size and weight of specific parts of their bodies, participants provided numerical estimates of either the weight or size of five chosen body parts. The five chosen measurements, in order of presentation in the study, were: head circumference (circumference around the forehead just above the eyes, in $\mathrm{cm}$ ), hand size (length from the tip of the middle finger to the beginning of the wrist, in $\mathrm{mm}$ ), heart weight (in oz), brain weight (in g) and lung capacity (in 1). We specified the units for head circumference, hand size, brain weight, heart weight and lung capacity in order to ensure that all participants made their estimates using the same metric. For each measurement, participants were given the actual average value for both men and women (for example, "The average head circumference for men is $56 \mathrm{~cm}$, and for women, $50 \mathrm{~cm}$. Please estimate (without measuring it) your own head circumference"). They were asked to use a slider to estimate their own body metrics. The default position of the slider was the centre of the scale and a wide range above and below the stated average was displayed. The chosen values were based on our search in medical and anatomical literature, and can be found in Appendix 1.

Narcissism was measured using the 40-item alternate forced choice Narcissistic Personality Inventory(NPI; Raskin \& Terry, 1988). For each item, participants were shown two statements and chose the one which applied most to them. One statement indicated high narcissism (e.g., "I know I am good because everybody keeps telling me so") and the other indicated low narcissism (e.g., "When people compliment me I sometimes get embarrassed"). One point was given for each high narcissism statement a participant chose (no points were given for selecting a low narcissism statement) and the sum of all points given measured overall narcissism (range $=1-33$, Cronbach's $\alpha=.84$ ). In this study, we used the three factor structure (Ackerman et al., 2011) which gives three sub-scales of narcissism: Leadership/Authority (Cronbach's $\alpha=$.76), Grandiose Exhibitionism (Cronbach's 
$\alpha=.75)$ and Entitlement/Exploitativeness (Cronbach's $\alpha=.47)$. The lower level of internal consistency for the Entitlement/Exploitativeness subscale is not unusual (Ackerman et al., 2011) and is in line with other research (e.g., Blinkhorn, Lyons, \& Almond, 2015, 2016, 2018; Vonk, Zeigler-Hill, Mayhew, \& Mercer, 2013).

\section{Procedure}

The first page of the online survey contained the participant information sheet, which outlined the relevant ethical information and the procedure of the study. Participants were told that we were interested in personality and how people perceive their own bodies. After clicking "Continue" to give informed consent to begin the study, participants completed a series of demographic questions (sex, age, nationality, current country of residence and occupation). Succeeding this they estimated either the size or weight of the five chosen body parts, and then completed the NPI. They were then thanked and presented with a full debrief.

\section{Results and Discussion}

Table 1 presents the descriptive statistics and sex differences for all measures. Men estimated all five body parts as greater than women (this was unsurprising since the provided average was always greater for males). Interestingly, there were no sex differences in total narcissism, or any of the NPI subscales.

To find whether participants estimated their body parts as greater or smaller than the average, we subtracted from their estimate the average stated for their sex (estimated size - relevant average), so that positive values represented estimates above the average and negative values represented estimates below the average. One-sample $t$-tests revealed that women significantly overestimated the circumference of their head in comparison to the average $[t(242)=3.71, p<.001]$, whereas men did $\operatorname{not}[t(72)=1.34, p=.20]$. Both men $[t(72)=$ $-2.41, p=.02]$, and women $[t(242)=4.00, p<$ $.001]$ estimated their hand size below the stated average. For women, heart weight was estimated

Table 1 Descriptive statistics and sex differences for all measures in Study 1

\begin{tabular}{|c|c|c|c|c|}
\hline & \multicolumn{3}{|c|}{ Mean $(S D)$} & \multirow[t]{2}{*}{$t$} \\
\hline & $\begin{array}{l}\text { Overall } \\
n=316\end{array}$ & $\begin{array}{l}\text { Males } \\
n=73\end{array}$ & $\begin{array}{c}\text { Females } \\
n=243\end{array}$ & \\
\hline Head circumference $(\mathrm{cm})$ & $52.57(5.81)$ & $56.96(5.41)$ & $52.25(5.26)$ & $8.07 * *$ \\
\hline Hand size (mm) & $171.80(17.04)$ & $184.56(15.74)$ & $168.02(15.52)$ & $7.96^{* *}$ \\
\hline Heart weight (oz) & $9.51(1.36)$ & $10.64(1.23)$ & $9.17(1.20)$ & $9.09 * *$ \\
\hline Brain weight $(\mathrm{g})$ & $1222.58(151.33)$ & $1327.96(143.94)$ & $1119.53(138.88)$ & $7.33 * *$ \\
\hline Lung capacity (l) & $4.61(1.12)$ & $5.58(0.89)$ & $4.31(1.00)$ & $9.75^{* *}$ \\
\hline Total NPI & $12.72(6.73)$ & $12.81(6.46)$ & $12.69(6.82)$ & 0.13 \\
\hline Leadership/Authority & $4.22(2.80)$ & $4.37(2.60)$ & $4.18(2.86)$ & 0.51 \\
\hline Grandiose Exhibitionism & $2.62(2.35)$ & $2.49(2.28)$ & $2.69(2.37)$ & -0.62 \\
\hline Entitlement/Exploitativeness & $0.84(1.01)$ & $0.88(0.99)$ & $0.83(0.83)$ & 0.37 \\
\hline
\end{tabular}

$* * * p<.001, * * p<.01, * p<.05$ 
as significantly greater than average, $[t(242)=$ $2.16, p<.001]$. No other estimates were significantly different to the stated average (see Table 2).
The relationships between the estimations of body size and the NPI (both total, and subscales) are presented in Table 3. We present correlations $(r)$ and unstandardized beta val-

Table 2 Mean difference between the stated average and estimated body size in Study 1. Positive values represent an average estimate above the average, negative values represent an average estimate below the average

\begin{tabular}{lccc}
\hline & \multicolumn{3}{c}{ Mean $(S D)$} \\
\cline { 2 - 4 } & Overall & Males & Females \\
& $n=316$ & $n=73$ & $n=243$ \\
\hline Head circumference $(\mathrm{cm})$ & $2.57(5.81)$ & $0.96(5.41)$ & $1.25(5.26)$ \\
Hand size $(\mathrm{mm})$ & $-4.08(15.54)$ & $-4.44(15.74)$ & $-3.98(15.52)$ \\
Heart weight $(\mathrm{oz})$ & $-0.16(1.21)$ & $0.14(1.27)$ & $0.17(1.17)$ \\
Brain weight $(\mathrm{g})$ & $-7.30(139.83)$ & $-8.04(143.93)$ & $-7.07(138.87)$ \\
Lung capacity $(\mathrm{l})$ & $0.04(0.99)$ & $-0.22(0.90)$ & $0.11(1.00)$ \\
\hline
\end{tabular}

Table 3 Zero-order correlations and standardised regression coefficients for NPI subscales and estimated body size in Study 1: presented as: $r(\beta)$

\begin{tabular}{|c|c|c|c|c|}
\hline & $\begin{array}{c}\text { Leadership / } \\
\text { Authority } \\
r(\beta)\end{array}$ & $\begin{array}{c}\text { Grandiose } \\
\text { Exhibitionism } \\
r(\beta)\end{array}$ & $\begin{array}{c}\text { Entitlement / } \\
\text { Exploitativenes } \\
r(\beta)\end{array}$ & $\begin{array}{c}\text { Total } \\
\text { NPI } \\
r\end{array}$ \\
\hline Overall $(n=316)$ & & & & \\
\hline $\begin{array}{l}\text { 1. Head circumference }(\mathrm{cm}) \\
\text { 2. Hand size }(\mathrm{mm}) \\
\text { 3. Heart weight }(\mathrm{oz}) \\
\text { 4. Brain weight }(\mathrm{g}) \\
\text { 5. Lung capacity }(\mathrm{l})\end{array}$ & $\begin{array}{c}.03(-.04) \\
.05(.09) \\
.03(.05) \\
.12 * *(.17) * * \\
.13 * *(.06)\end{array}$ & $\begin{array}{l}.06(.04) \\
-.03(-.08) \\
-.01(-.02) \\
.01(-.06) \\
.14 * *(.09)\end{array}$ & $\begin{array}{c}.15 * *(.16)^{* * *} \\
.02(.02) \\
-.02(-.03) \\
-.02(.05) \\
.11(.07)\end{array}$ & $\begin{array}{l}.09 \\
.02 \\
.05 \\
.08 \\
.17^{* *}\end{array}$ \\
\hline $\begin{array}{l}\text { Males }(n=73) \\
\text { 1. Head circumference }(\mathrm{cm}) \\
\text { 2. Hand size }(\mathrm{mm}) \\
\text { 3. Heart weight }(\mathrm{oz}) \\
\text { 4. Brain weight }(\mathrm{g}) \\
\text { 5. Lung capacity }(\mathrm{l})\end{array}$ & $\begin{array}{c}.28 *(.26)^{*} \\
.17(.27) \\
.12(.18) \\
.30 * *(.35)^{* * *} \\
.10(.07)\end{array}$ & $\begin{array}{l}.21(.03) \\
-.04(-.13) \\
-.07(-.14) \\
.02(-.10) \\
.10(.07)\end{array}$ & $\begin{array}{l}.21(.223) \\
-.06(-.03) \\
-.05(-.02) \\
-.10(-.08) \\
.01(-.02)\end{array}$ & $\begin{array}{l}.33^{* *} \\
.11 \\
.08 \\
.25^{*} \\
.10\end{array}$ \\
\hline $\begin{array}{l}\text { Females }(n=243) \\
\text { 1. Head circumference }(\mathrm{cm}) \\
\text { 2. Hand size }(\mathrm{mm}) \\
\text { 3. Heart weight }(\mathrm{oz}) \\
\text { 4. Brain weight }(\mathrm{g}) \\
\text { 5. Lung capacity }(\mathrm{l})\end{array}$ & $\begin{array}{l}-.06(-.16)^{*} \\
-.01(.01) \\
.01(-.04) \\
.06(.08) \\
.14 * *(.02) \\
\end{array}$ & $\begin{array}{c}.04(.09) \\
.04(-.03) \\
-.02(.07) \\
.03(-.010) \\
.20^{* * *}(.17)^{* * *} \\
\end{array}$ & $\begin{array}{l}.13 *(.16) \\
-.03(.04) \\
.04(-.03) \\
-.01(-.03) \\
.14 * *(.10)\end{array}$ & $\begin{array}{l}.03 \\
.04 \\
-.01 \\
.04 \\
.21 * * *\end{array}$ \\
\hline
\end{tabular}


ues $(\beta)$ for the overall data, and then separately for men and women. Overall, estimated head circumference was positively associated with Entitlement/Exploitativeness, estimated brain weight was positively associated with Leadership/Authority, and estimated lung capacity was positively associated with overall narcissism, Leadership/Authority and Grandiose Exhibitionism. In men, estimated head circumference was positively correlated with overall narcissism, Leadership/Authority, Entitlement/ Exploitativeness, and brain weight was positively correlated with overall narcissism and Leadership/Authority. In women, estimated head circumference was positively correlated with Entitlement/Exploitativeness and negatively correlated with Leadership/Authority. In addition, perceived lung capacity in women was positively correlated with overall narcissism and all three sub-scales.

When shared variance between the subscales of the NPI were controlled for using simultaneous linear multiple regressions, in the total sample, Entitlement/Exploitativeness predicted greater estimates of head circumference, Leadership/Authority predicted greater estimates of brain weight, and Grandiose Exhibitionism predicted greater estimated lung capacity. In men, Leadership/Authority predicted greater estimates of head circumference and estimated brain weight. In women, Leadership/ Authority negatively predicted estimated head circumference and Entitlement/Exploitativeness positively predicted estimated head circumference.

Using Fisher's $r$-to- $z$ transformation, we found that the effect of Leadership/Authority on estimated head circumference differed between the sexes $[z=2.57, p=.01]$. This shows that men who scored higher on Leadership/ Authority estimated their heads as bigger, whereas women who scored higher on the same trait estimated their heads as smaller. No other sex differences were found.
The results of Study 1 showed that especially the Leadership/Authority facet of narcissism predicted sex-specific biases in estimates of body size-specifically greater estimates of head circumference and brain weight. Men (but not women) with higher levels of the adaptive subcomponent of narcissism overestimated their brain weight and head circumference. This could be related to the tendency of narcissistic men to over-enhance their intelligence (Gabriel et al., 1994). Our results suggest that this tendency could be localised to the Leadership/Authority facet. The Leadership/Authority facet was, interestingly, marginally negatively correlated with estimated head circumference in women.

These sex differences could be linked to the association between perceived intelligence and head circumference, and sex differences in the importance of intelligence when choosing a partner. Rather than an asset, intelligence could be a handicap for women in initial dating situations (Karbowski, Deja, \& Zawisza, 2016). In contrast, intelligence could be beneficial for men, as women are attracted to men they perceive as intelligent (Karbowski et al., 2016). It is possible (although not yet investigated) that individuals subconsciously infer intelligence of others from their head size. Perceptions of intelligence (Kleisner, Chvátalová, \& Flegr, 2014; Lee et al., 2017), and actual intelligence (Lee et al., 2017) is related to larger distance between the eyes and this distance is positively correlated with head size (Fledelius, 1982). Perhaps individuals with high levels of the adaptive facet of narcissism have stronger intuition about what the opposite sex finds attractive, and tune their head size estimations to reflect this.

Since sex-specific averages were given, it is possible that the opposite directions in estimated head circumferencereflect differences in withinsex competitive strategies. For example, due to a general tendency in current Western society for female attractiveness to be centred on thinness and petiteness (Hesse-Biber, 1996), narcissistic 
females may infer that smaller head size is considered more attractive. This desire to be viewed as more attractive and superior to other females may have led them to estimate below the stated average. This finding generally agrees with other research that has found a relationship between narcissism and sexual competitiveness in women (Carter et al., 2015). For men, evidence has suggested that there exists a powerful stereotype of the physical appearance of a male leader. This stereotypical male leader is tall(Gladwell, 2005), has a deep voice (Klofstad, Anderson, \& Peters, 2012; Mayew, Parsons, \& Venkatachalam, 2013) and is physically fit (Limbach \& Sonnenburg, 2014). Our results suggest that men who scored higher on the Leadership/Authority facet may have been inferring an ideal head size from, and therefore conforming with, this widely held stereotype.

\section{Study 2}

In Study 1 we provided participants with sexspecific average values for each body part. If the opposing influence of scoring higher on the Leadership/Authority facet of the NPI on estimates of head size for males and females was due to differences in within-sex competitive strategies, then we might expect this effect to disappear if no differentiation is made between the sexes. Specifically, if sex-specific averages are not provided, we may find that both sexes scoring higher on Leadership/Authority estimate their head circumference as greater due to general tendency for individuals scoring high on this facet being driven to be seen as superior to others.

\section{Method}

\section{Participants}

The sample consisted of 275 participants (mean age $=23.40, S D=7.10 ; 22.18 \%$ male). Par- ticipants were recruited by advertising an online questionnaire to students at a university in North-West of England, who could participate for course credit. The questionnaire was also shared with the wider community via social media.

\section{Materials}

Narcissism was measured in the same way as in Study 1, using the NPI (Raskin \& Terry, 1988). One point was given for each high narcissism statement a participant chose (no points were given for selecting a low narcissism statement) and the sum of all points given indicates overall narcissism (range $=2-39$, Cronbach's $\alpha=.86)$. We used the three factor structure (Ackerman et al., 2011), which gives three sub-scales of narcissism: Leadership/Authority(Cronbach's $\alpha=.77$ ), Grandiose Exhibitionism (Cronbach's $\alpha=.77$ ), and Entitlement/Exploitativeness (Cronbach's $\alpha=$ .47). The lower level of internal consistency for the Entitlement/Exploitativeness subscale is not unusual (Ackerman etal., 2011) and is in line with other research (e.g., Vonk etal., 2013).

To measure perceived body size and weight of specific parts of their body, participants provided numerical estimates of either the weight or size of the same five body parts as in Study 1. However, instead of being provided with a single specific average value, participants were given a range of values (for example, "The average head circumference varies between 48 and $60 \mathrm{~cm}$. Please estimate (without measuring it) your own head circumference"). Participants moved a slider to make their estimate as in Study 1 , and the given ranges for each body part were the same as in Study 1. The chosen values were based on our search in medical and anatomical literature, and can be found in Appendix 1 .

\section{Procedure}

The procedure was identical to Study 1 . 


\section{Results and Discussion}

Table 4 summarises the descriptive statistics and sex differences for all measures. Men estimated all five body parts as significantly greater than women. This suggests that the tendency for men to estimate their body parts as greater than women was not due to the presence of separate sex-specific average values in Study 1. In terms of narcissism, men scored significantly higher on Grandiose Exhibitionism than women, but no other sex differences were found.

The relationships between the estimations of body size and the sub-scales of the NPI are presented in Table 5. We present correlations $(r)$ and unstandardized beta values $(\beta)$ for the overall data, and then separately for the sexes. Overall, estimated head circumference and lung capacity were positively associated with Leadership/Authority, Entitlement/Exploitation, and overall narcissism. For men, estimated heart weight was positively associated with Leadership/Authority. For women, estimated head circumference was positively associated with Leadership/Authority and Entitlement/
Exploitativeness, and estimated lung capacity was positively associated with Entitlement/ Exploitativeness. When the shared variance between the sub-scales of the NPI were controlled for using multiple regressions, overall, Leadership/Authority and Entitlement/ Exploitativeness predicted greater estimates of head circumference and lung capacity. For men, Leadership/Authority predicted greater estimates of heart weight. For women, Entitlement/ Exploitativeness significantly predicted greater estimates of head circumference and lung capacity, and Grandiose Exhibitionism predicted lower estimates of heart weight. However, when we tested the differences in the strength of the correlations between the sexes using Fisher's $r$-to- $z$ transformation, none of them were significantly different.

The results of Study 2 indicate that the presence or absence of a frame of reference affected the relationship between narcissism and body perception. As we suspected, the opposing effect of Leadership/Authority for estimates of head size in males and females disappeared in Study 2, and instead we found that this facet predicted greater estimates of head circumfer-

Table 4 Descriptive statistics and sex differences for all measures in Study 2

\begin{tabular}{|c|c|c|c|c|}
\hline & \multicolumn{3}{|c|}{ Mean $(S D)$} & \multirow[t]{2}{*}{$t$} \\
\hline & $\begin{array}{l}\text { Overall } \\
n=275\end{array}$ & $\begin{array}{l}\text { Males } \\
n=61\end{array}$ & $\begin{array}{c}\text { Females } \\
n=212\end{array}$ & \\
\hline Head circumference $(\mathrm{cm})$ & $55.33(9.18)$ & $60.16(9.76)$ & $53.95(8.56)$ & $4.85 * * *$ \\
\hline Hand size (mm) & $171.08(20.59)$ & $180.71(18.17)$ & $168.33(20.46)$ & $4.27 * * *$ \\
\hline Heart weight (oz) & $9.91(1.79)$ & $10.6(1.89)$ & $9.71(1.73)$ & $3.50 * * *$ \\
\hline Brain weight (g) & $1302.21(172.82)$ & $1367.49(179.71)$ & $1283.60(66.60)$ & $3.41 * * *$ \\
\hline Lung capacity (l) & $5.44(1.93)$ & $6.30(2.71)$ & $5.19(1.56)$ & $4.06^{* * *}$ \\
\hline Total NPI & $14.31(7.05)$ & $15.61(7.04)$ & $13.94(7.03)$ & 1.63 \\
\hline Leadership/Authority & $5.21(2.79)$ & $5.75(2.84)$ & $5.05(2.76)$ & 1.74 \\
\hline Grandiose Exhibitionism & $2.84(2.47)$ & $3.51(2.35)$ & $2.65(2.47)$ & $2.42 * *$ \\
\hline Entitlement/Exploitativeness & $0.83(1.00)$ & $1.00(1.05)$ & $0.78(0.98)$ & 1.55 \\
\hline
\end{tabular}


Table 5 Zero-order correlations and standardised regression coefficients for NPI subscales and estimated body size in Study 2: presented as: $r(\beta)$

\begin{tabular}{|c|c|c|c|c|}
\hline & $\begin{array}{c}\text { Leadership / } \\
\text { Authority } \\
r(\beta)\end{array}$ & $\begin{array}{c}\text { Grandiose } \\
\text { Exhibitionism } \\
r(\beta)\end{array}$ & $\begin{array}{c}\text { Entitlement / } \\
\text { Exploitativenes } \\
r(\beta)\end{array}$ & $\begin{array}{c}\text { Total NPI } \\
r \\
\end{array}$ \\
\hline Overall $(n=275)$ & & & & \\
\hline $\begin{array}{l}\text { 1. Head circumference }(\mathrm{cm}) \\
\text { 2. Hand size }(\mathrm{cm}) \\
\text { 3. Heart weight }(\mathrm{oz}) \\
\text { 4. Brain weight }(\mathrm{kg}) \\
\text { 5. Lung capacity }(\mathrm{l})\end{array}$ & $\begin{array}{c}.12 * * *(.17 * *) \\
-03(.04) \\
.11\left(.19^{* * *}\right) \\
.07(.03) \\
.18^{* * *}\left(.17^{* *}\right)\end{array}$ & $\begin{array}{l}.12(.02) \\
-.02(-.05) \\
-.07(-.13) \\
.08(.04) \\
.07(-.03)\end{array}$ & $\begin{array}{l}.13 * *(.06) \\
.04(.05) \\
.04(-.06) \\
.09(.07) \\
.12 * *(.07)\end{array}$ & $\begin{array}{l}.20^{* * *} \\
.01 \\
.02 \\
.12^{* *} \\
.17^{* *}\end{array}$ \\
\hline $\begin{array}{l}\text { Males }(n=61) \\
\text { 1. Head circumference }(\mathrm{cm}) \\
\text { 2. Hand size }(\mathrm{cm}) \\
\text { 3. Heart weight }(\mathrm{oz}) \\
\text { 4. Brain weight }(\mathrm{kg}) \\
\text { 5. Lung capacity }(\mathrm{l})\end{array}$ & $\begin{array}{c}.20(.23) \\
.23(.26) \\
.36^{* * *}\left(.40^{* * *}\right) \\
.07(.07) \\
.25(.25)\end{array}$ & $\begin{array}{l}.15(.16) \\
-.06(-.13) \\
-.01(-.07) \\
.06(.06) \\
.10(.06)\end{array}$ & $\begin{array}{l}-.10(-.22) \\
.05(.02) \\
-.01(-.10) \\
-.02(-.07) \\
.04(-.05)\end{array}$ & $\begin{array}{l}.18 \\
.15 \\
.25 \\
.09 \\
.21\end{array}$ \\
\hline $\begin{array}{l}\text { Females }(n=212) \\
\text { 1. Head circumference }(\mathrm{cm}) \\
\text { 2. Hand size }(\mathrm{cm}) \\
\text { 3. Heart weight }(\mathrm{oz}) \\
\text { 4. Brain weight }(\mathrm{kg}) \\
\text { 5. Lung capacity }(\mathrm{l})\end{array}$ & $\begin{array}{l}17 *(.15) \\
-.05(-.05) \\
.01(.10) \\
.05(.01) \\
.13(.12) \\
\end{array}$ & $\begin{array}{c}.06(-.07) \\
-.05(-.05) \\
-.13\left(-.16^{* *}\right) \\
.05(.01) \\
.01(-.10) \\
\end{array}$ & $\begin{array}{l}.18 * * *(.15) \\
.01(.05) \\
-.07(-.05) \\
.11(.10) \\
.14 * *(.13) \\
\end{array}$ & $\begin{array}{l}.17^{*} \\
-.05 \\
-.08 \\
.11 \\
.13\end{array}$ \\
\hline
\end{tabular}
$* * * p<.001,{ }^{* *} p<.01,{ }^{*} p<.05$

ence overall. These results indirectly suggest that the results of Study 1 reflected a difference in within-sex competitive strategies, and that when the pressure associated with being given a sex-specific average is removed, Leadership/ Authority predicts greater estimates of head circumference overall. To further test whether this is indeed the case, it would be useful to have the same participants estimate head size both with and without a reference and also assess the extent to which they experience social pressure to conform to beauty standards however this was not done here due to the exploratory nature of the present work. Interestingly, this facet Leadership/Authority also predicted greater estimates of heart weight and lung capacity. The relationship between estimating a bigger heart is surprising and contrary to what we expected. Although narcissists self-enhance agentic rather than communal traits (Grijalva \& Zhang, 2016), they also sometimes engage in public pro-social behaviour (Konrath, Ho, \& Zarins, 2016). Perhaps the self-estimated heart weight is a result of self-perceived altruism that narcissists could have as a result of their explicit, rather than genuinely implicit, occasional tendency to help others.

\section{General Discussion}

In two studies, we investigated whether narcissism predicts biases in perceived size of different body parts, depending on the sex of the individual. In Study 1, we gave participants es- 
timates of average sizes within their own sex, and found that Leadership/Authority predicted greater estimates of head circumference in men but lower estimates in women. This difference could signal differences in within-sex competitive strategies and a desire to be seen in a particular way relative to other members of the same sex. Specifically, we suggested that, for females, attractiveness in current Western society is largely based on striving for thinness and petiteness (Hesse-Biber, 1996), narcissistic females may estimate their heads as smaller so that they might be considered more attractive. Evidence that shows a positive relationship between narcissism and sexual competitiveness in women (Carter et al., 2015) supports this suggestion. There is a vast literature on physical attractiveness for females, and factors identified as indicating attractiveness include small foot size, for example (Fessler et al., 2012). Women are on average smaller than men, and it is plausible that narcissistic females estimated their heads as smaller to be considered more attractive.

In contrast, men who scored higher on the Leadership/Authority facet may have been inferring an ideal head size from a powerful stereotype of a male leader (e.g., Gladwell, 2005), and therefore inflated their estimates of their own head size in order to conform to this stereotype. In addition, being taller is also considered more attractive in men (Pawlowski, Dunbar, \& Lipowicz, 2000), and height is associated with both larger head circumference and intelligence (Lynn, 1989). Thus, men who scored high on the Leadership/Authority facet engaged in selfenhancement of a body size that related to other evolutionarily relevant mating-related variables. Our assertion that the opposing effect of Leadership/Authority on male and female estimates reflected within-sex competitive strategies was supported by the results of Study 2. In Study 2, we did not provide sex-specific averages for body part size, there was no overt within-sex competition, and we found that the sex difference in Study 1 was not present. Instead, we found that Leadership/Authority predicted greater estimates of head circumference overall.

Taken together, our results suggest a relationship between narcissism and self-enhancement in body parts that are relevant in sexual selection. Our results suggest that narcissism predicts biases in perceived head size, but that the exact nature of this relationship is dependent on the frame of reference estimates of head size are made in. Future work should note the effect of framing questions in ways that may induce a sense of competitiveness in respondents on the outcomes of studies, in particular when investigating narcissism.

Although these studies provide interesting preliminary results in an under-investigated aspect of narcissism and perception of size of body parts, the results should be treated with caution. First, it is possible that the relationship between narcissism and perceived size of specific body parts is mediated by lifestyle factors such as exercise and diet choices. Perhaps lung size estimations made by highly narcissistic individuals are larger because they associate lung size with cardiovascular fitness. Future work in this area should consider measuring lifestyle factors that could be related to narcissism in order to investigate such possible mediation further. Second, we gathered participants primarily using social media and this gave us wide and varied samples in terms of age and nationality, but both studies contained more females than males. However, it is noteworthy that we found Leadership/Authority predicted opposing effects on estimated head circumference in males and females, despite this sex imbalance in Study 1. The fact that this difference was not only statistically significant, but also predicted opposing effects, suggests that the sex imbalance may not have been problematic here. We also tested only self-reported head 
size. We suggest that actual head size should be measured in future work (see Bianchi et al., 2008). This would provide an opportunity to test whether narcissistic individuals overestimate their head size relative to their own true head size as well as to a given average. Since narcissism is characterised by favourable selfevaluations we suspect that the relationship between narcissism and estimated head size found in these studies may reflect a drive to appear superior to others, and therefore may not be found when estimates are compared to true head size.

There were some discrepancies between the findings of Studies 1 and 2 that should be discussed further. Although some of these differences are explained by our idea that removing sex-specific average values for body size induced within-sex competition strategies in Study 1 , there are some differences which may be more peculiar. For example, we found that greater Leadership/Authority predicted greater estimated brain weight overall and in males in Study 1, but this was not replicated in Study 2 . This provides some support for the argument that our results broadly show that the reported relationships between narcissism and perceived body size relate primarily to attractiveness and a desire to be perceived as attractive, rather than intelligence. However, future research is required to fully understand the relationships between narcissism and perceived body size, in particular for body parts which may carry more subtle social messages. Furthermore, although we attempted to recruit a broad sample, a large portion of the sample were young university students and so the generalisability of our results is not certain. This is a widely discussed issue in psychological research, notable from the idea of WEIRD (Western, educated, industrialised, rich, and democratic, in Henrich, Heine, \& Norenzayan, 2010) samples and should be considered more generally in psychological research.
Overall, the results of the present studies suggest that narcissism predicts biases in selfreported perceived head size, although the precise nature of these biases is dependent on the frame of reference in which head size estimates are made. The influence of the frame of reference highlights an interesting interaction between personality, perceived body size and social expectation.

\section{References}

Ackerman, R. A., Witt, E. A., Donnellan, M. B., Trzesniewski, K. H., Robins, R. W., \& Kashy, D. A. (2011). What does the narcissistic personality inventory really measure? Assessment, 18, 67-87. doi: 10.1177/1073191110382845

Alberti, F. B. (2016). This mortal coil: The human body in history and culture. Oxford University Press.

Bakhiet, S. F. A., Essa, Y. A. S., Dwieb, A. M. M., Elsayed, A. M. A., Sulman, A. S. M., Cheng, H., \& Lynn, R. (2017). Correlations between intelligence, head circumference and height: Evidence from two samples in Saudi Arabia. Journal of Biosocial Science, 49, 276-280. doi: 10.1017/ S0021932016000249.

Blinkhorn, V., Lyons, M., \& Almond, L. (2015). The ultimate femme fatale? Narcissism predicts serious and aggressive sexually coercive behaviour in females. Personality and Individual Differences, 87 , 219-223. https://doi.org/10.1016/j.paid.2015.08. 001 .

Blinkhorn, V., Lyons, M., \& Almond, L. (2016). Drop the bad attitude! Narcissism predicts acceptance of violent behaviour. Personality and Individual Differences, 98, 157-161. https://doi.org/10.1016/ j.paid.2016.04.025.

Blinkhorn, V., Lyons, M., \& Almond (2018). Criminal minds: Narcissism predicts offending behavior in a non-forensic sample. Deviant Behavior, 40(3), 353 360. doi: 10.1080/01639625.2017.1422458.

Bruno, A., Quattrone, D., Scimeca, G., Cicciarelli, C., Romeo, V. M., Pandolfo, G., ... \& Muscatello, M. R. A. (2014). Unraveling exercise addiction: The role of narcissism and self-esteem. Journal of Addiction, vol. 2014. Article ID 987841. http://dx.doi.org/ 10.1155/2014/987841.

Campbell, W. K., Rudich, E. A., \& Sedikides, C. (2002). Narcissism, self-esteem, and the positivity of selfviews: Two portraits of self-love. Personality and Social Psychology Bulletin, 28, 358-368. doi: 10.1177 .0146167202286007 . 
Carrotte, E., \& Anderson, J. (2019). Risk factor or protective feature? The roles of grandiose and hypersensitive narcissism in explaining the relationship between self-objectification and body image concerns. Sex Roles, 80, 458-468. doi: 10.1007/ s11199-018-0948-y.

Carter, G. L., Montanaro, Z., Linney, C., \& Campbell, A. C. (2015). Women's sexual competition and the Dark Triad. Personality and Individual Differences, 74, 275-279. https://doi.org/10.1016/j.paid.2014. 10.022 .

Fessler, D. M., Nettle, D., Afshar, Y., de Andrade Pinheiro, I., Bolyanatz, A., Mulder, M. B., ... \& Khaltourina, D. (2005). A cross-cultural investigation of the role of foot size in physical attractiveness. Archives of Sexual Behavior, 34, 267-276. doi: $10.1007 / \mathrm{s} 10508-005-3115-9$.

Fledelius, H. C. (1982). Inhibited growth and development as permanent features of low birth weight. A longitudinal study of eye size, height, head circumference, interpupillary distance and exophthalmometry, as measured at age of 10 and 18 years. Acta Pcediatrica, 71, 645-650. https://doi.org/10.1111/ j.1651-2227.1982.tb09490.x.

Gabriel, M. T., Critelli, J. W., \& Ee, J. S. (1994). Narcissistic illusions in selfevaluations of intelligence and attractiveness. Journal of Personality, 62, 143155. doi: 10.1111/j.1467-6494.1994.tb00798.x.

Gibbs Jr., R. W. (2003). Embodied experience and linguistic meaning. Brain and Language, 84, 1-15. doi: 10.1016/S0093-934X(02)00517-5.

Gladwell, M. (2007). Blink: The power of thinking without thinking. Back Bay Books.

Goncalo, J. A., Flynn, F. J., \& Kim, S. H. (2010). Are two narcissists better than one? The link between narcissism, perceived creativity, and creative performance. Personality and Social Psychology Bulletin, 36, 1484-1495. doi: 10.1177/ 0146167210385109.

Grijalva, E., \& Zhang, L. (2016). Narcissism and selfinsight: A review and meta-analysis of narcissists' self-enhancement tendencies. Personality and Social Psychology Bulletin, 42, 3-24. doi: 10.1177/ 0146167215611636.

Hesse-Biber, S. J. (1996). Am I thin enough yet? The cult of thinness and the commercialization of identity. Oxford University Press.

Henrich, J., Heine, S. J., \& Norenzayan, A. (2010). The weirdest people in the world? Behavioral and Brain Sciences, 33, 61-83. doi: 10.1017/ S0140525X0999152X

Jonason, P. K., Lyons, M., Bethell, E. J., \& Ross, R. (2013). Different routes to limited empathy in the sexes: Examining the links between the Dark Triad and empathy. Personality and Individual Differences, 54, 572-576. https://doi.org/10.1016/j.paid.2012. 11.009 .

Karbowski, A., Deja, D., \& Zawisza, M. (2016). Perceived female intelligence as economic bad in partner choice. Personality and Individual Differences, 102, 217-222. https://doi.org/10.1016/ j.paid.2016.07.006.

Kleisner, K., Chvátalová, V., \& Flegr, J. (2014). Perceived intelligence is associated with measured intelligence in men but not women. Public Library of Science One, 9, e81237. doi: 10.1371/journal. pone.0081237.

Klofstad, C. A., Anderson, R. C., \& Peters, S. (2012). Sounds like a winner: Voice pitch influences perception of leadership capacity in both men and women. Proceedings of the Royal Society of London B: Biological Sciences. https://oi.org/10.1098/ rspb.2012.0311 rspb20120311.

Konrath, S., Meier, B. P., \& Bushman, B. J. (2014). Development and validation of the single item narcissism scale (SINS). Public Library of Science One, 9. doi: 10.1371/journal.pone.0103469.

Konrath, S., Ho, M. H., \& Zarins, S. (2016). The strategic helper: Narcissism and prosocial motives and behaviors. Current Psychology, 35, 182-194. doi: 10.1007/s12144-016-9417-3.

Krizan, Z., \& Bushman, B. J. (2011). Better than my loved ones: Social comparison tendencies among narcissists. Personality and Individual Differences, 50, 212-216. https://doi.org/10.1016/j.paid. 2010.09 .031 .

Lee, A. J., Hibbs, C., Wright, M. J., Martin, N. G., Keller, M. C., \& Zietsch, B. P. (2017). Assessing the accuracy of perceptions of intelligence based on heritable facial features. Intelligence, 64, 1-8. https://doi.org/10.1016/j.intell.2017.06.002.

Limbach, P., \& Sonnenburg, F. (2015). CEO fitness and firm value. Available at SSRN 2489967.

Lipowska, M., \& Lipowski, M. (2015). Narcissism as a moderator of satisfaction with body image in young women with extreme underweight and obesity. Public Library of Science One, 10. https://doi.org/10.1371/ journal.pone.0126724.

Lynn, R. (1989). A nutrition theory of the secular increases in intelligence; positive correlations between height, head size and IQ. British Journal of Educational Psychology, 59, 372-377. doi: 10.1111/j.2044-8279.1989.tb03112.x.

Nave, G., Jung, W. H., Karlsson Linnér, R., Kable, J. W., \& Koellinger, P. D. (2019). Are bigger brains smarter? Evidence from a large-scale preregistered study. Psychological science, 30, 43-54. doi: $10.1177 / 0956797618808470$. 
Pietschnig, J., Penke, L., Wicherts, J. M., Zeiler, M. \& Voracek, M. (2015). Meta-analysis of associations between human brain volume and intelligence differences: How strong are they and what do they mean? Neuroscience \& Biobehavioral Reviews, 57 , 411-432. doi: 10.1016/j.neubiorev.2015.09.017.

Pawlowski, B., Dunbar, R. I. M. \& Lipowicz, A. (2000). Tall men have more reproductive success. Nature, 403(6766), 156. doi: 10.1038/35003107.

Purton, T., Officer, C., Bullivant, B., Mitchison, D., Griffiths, S., Murray, S. B., \& Mond, J. (2018). Body dissatisfaction, narcissism and self-esteem in young men and women: A moderated mediation analysis. Personality and Individual Differences, 131, 99104. https://doi.org/10.1016/j.paid.2018.04.010.

Raskin, R., \& Terry, H. (1988). A principal-components analysis of the Narcissistic Personality Inventory and further evidence of its construct validity. Journal of Personality and Social Psychology, 54(5), 890-902. doi: 10.1037/0022-3514.54.5.890.
Rauthmann, J. F. (2012). The Dark Triad and interpersonal perception: Similarities and differences in the social consequences of narcissism, Machiavellianism, and psychopathy. Social Psychological and Personality Science, 3, 487-496. doi: 10.1177/ 1948550611427608.

Swami, V., Cass, L., Waseem, M., \& Furham, A. (2015). What is the relationship between facets of narcissism and women's body image? Personality and Individual Differences, 87, 185-189. https://doi.org/ $10.1016 /$ j.paid.2015.08.006.

Tsakiris, M. (2017). The multisensory basis of the self: From body to identity to others. The Quarterly Journal of Experimental Psychology, 70, 597-609. doi: 10.1080/17470218.2016.1181768.

Vonk, J., Zeigler-Hill, V., Mayhew, P., \& Mercer, S. (2013). Mirror, mirror on the wall, which form of narcissist knows self and others best of all? Personality and Individual Differences, 54, 396-401. https:// doi.org/10.1016/j.paid.2012.10.010.

\section{Appendix}

\section{Average values given for head circumference, hand length, brain weight, heart weight and lung capacity in Studies 1 and 2}

\section{Study 1}

\begin{tabular}{|l|c|c|c|}
\hline Measure & Given male average & Given female average & Given range on slider \\
\hline Head circumference $(\mathrm{cm})$ & 56 & 50 & $30-100$ \\
\hline Hand length $(\mathrm{mm})$ & 189 & 172 & $100-220$ \\
\hline Heart weight $(\mathrm{oz})$ & 10.5 & 9 & $0-20$ \\
\hline Brain weight $(\mathrm{g})$ & 1336 & 1198 & $0-2000$ \\
\hline Lung capacity $(\mathrm{l})$ & 5.8 & 4.2 & $1-20$ \\
\hline
\end{tabular}

\section{Study 2}

\begin{tabular}{|l|c|c|}
\hline Measure & Given average range & Given range on slider \\
\hline Head circumference $(\mathrm{cm})$ & $48-60$ & $30-100$ \\
\hline Hand length $(\mathrm{mm})$ & $170-192$ & $100-220$ \\
\hline Heart weight $(\mathrm{oz})$ & $8-12$ & $0-20$ \\
\hline Brain weight $(\mathrm{g})$ & $1170-1429$ & $0-2000$ \\
\hline Lung capacity $(\mathrm{l})$ & $4-6.5$ & $1-20$ \\
\hline
\end{tabular}

